\title{
Postprocessing of molecular docking poses using binding free energy calculations
}

\author{
Kanin Wichapong ${ }^{*}$, Wolfgang Sippl \\ From 7th German Conference on Chemoinformatics: 25 CIC-Workshop \\ Goslar, Germany. 6-8 November 2011
}

The main key to success in structure-based drug discovery is the accurate prediction of binding affinities of hit compounds. Molecular docking and scoring functions are often used for this purpose. However, it is often found that the top-ranked docking poses do not represent the right binding mode, and frequently there is no correlation between docking score and biological data. Therefore, "post-processing" of docking poses has recently got attraction. In previous work [1], we have successfully computed binding free energies (MM/PBSA) of 222 Wee1 kinase inhibitors and used the derived validated models for virtual screening. In the current work, we extended our studies to a data set of PIM1 kinase inhibitors. Crossdocking studies showed that the correct binding mode of the inhibitors can be determined after applying a post-processing procedure. The top-ranked docking poses gave wrong binding mode (high RMSD values $\sim 4.0 \AA$ ) ), whereas the top-ranked poses selected after postprocessing yielded RMSD values around $0.5 \AA$. Subsequently, the docking poses giving the lowest binding free energy were selected and these values were used to establish a correlation with experimental data. A significant correlation between $\Delta G_{\text {cal. }}$ and $\Delta \mathrm{G}_{\exp }\left(r^{2}=0.58\right)$ was obtained. To summarize, the protocol described in the current work can be used for postprocessing of protein-ligand docking poses and for predicting biological activities of novel hits. Therefore, the protocol can be applied for structure-based optimization of hit molecules.

Published: 1 May 2012

Reference

1. Wichapong K, Lawson M, Pianwanit S, Kokpol S, Sippl W: Postprocessing of Protein-Ligand Docking Poses Using Linear Response MM-PB/SA:

* Correspondence: kanin.wichapong@pharmazie.uni-halle.de Department of Pharmaceutical Chemistry, Martin-Luther University HalleWittenberg, 06120, Halle(Saale), Germany
Application to Wee1 Kinase Inhibitors. J Chem Inf Model 2010, 50:1574-1588.

doi:10.1186/1758-2946-4-S1-P42

Cite this article as: Wichapong and Sippl: Postprocessing of molecular docking poses using binding free energy calculations. Journal of Cheminformatics 2012 4(Suppl 1):P42.

\section{Publish with ChemistryCentral and every scientist can read your work free of charge \\ "Open access provides opportunities to our colleagues in other parts of the globe, by allowing anyone to view the content free of charge." \\ W. Jeffery Hurst, The Hershey Company. \\ - available free of charge to the entire scientific community \\ - peer reviewed and published immediately upon acceptance \\ - cited in PubMed and archived on PubMed Central \\ - yours - you keep the copyright \\ Submit your manuscript here: \\ http://www.chemistrycentral.com/manuscript/

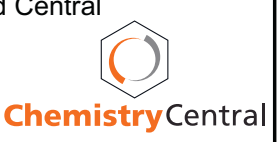

